\title{
MSM and HIV/AIDS in China
}

\author{
Bei Chuan ZHANG ${ }^{1, *}$, Quan Sheng $\mathrm{CHU}^{2}$ \\ ${ }^{1}$ Sex Health Center of the Affiliated Hospital of Medical College Qingdao University, Qingdao 266012, China \\ ${ }^{2}$ Qingdao Center for Diseases Control \& Prevention, Qingdao 266033, China
}

\begin{abstract}
This article profiles current status of spread and control of HIV/AIDS in China. China has a significant population of MSM (men who have sex with men) and they have been becoming very much alive in many ways since 1990s due to recent social changes. Some surveys indicate that great many of MSM are engaged in high-risk behaviors. In addition, majority of MSM have also experienced sexual encounters with women sometimes in their lives, which possibly contribute to spread of HIV to women. Some reports documented that HIV is becoming rampant among MSM since more than $1 \%$ of them are now infected. Political, cultural and custom elements could hinder intervention activities against HIV spread among MSM. Fortunately, many cities in China have seen that MSM were in cooperation with responsible institutions carrying out certain intervention measures. The general situation is promising. The authors forecast that the fast HIV spread among MSM of China could possibly be halted within several years when the authorities become more sensible to this issue, health service institutions offer unswerving efforts toward the MSM community and those who involve in MSM undertakes necessary responsibilities.
\end{abstract}

Keywords: MSM, gay, HIV/AIDS, China.

\section{INTRODUCTION}

The term MSM (men who have sex with men) was introduced into mainland China in 2000. Homosexuals, without identifying gender, were used previously to describe MSM by authorities, the public and even professionals. The first confirmed MSM case, a man in Beijing, in mainland China was in 1989. MSM accounts for $0.2 \%$ of reported cases of HIV/AIDS in China by 2001 [1]. An unpublished study orchestrated by several authoritative institutions predicted that the MSM proportion may reach as high as $15 \%$ by 2010 . An official document issued in 2004 indicated that sexually transmitted HIV/AIDS cases accounted for $30.9 \%$ of all HIV/AIDS cases in the year 2003, with MSM contributing 11.1\% [2].

Restricted by political, cultural and custom elements [3], China is lagging behind in study on relationship between MSM and HIV/AIDS, and lacking involved data and corresponding health interventions as well. Fortunately,

*Correspondance: Bei Chuan ZHANG

Tel: 86-532-271-0247; Fax: 86-532-271-0247;

E-mail: pytx@263.net spread of HIV/AIDS via MSM is sparking more and more concerns in China and a critical turning point is looming [4]. Goal of this article is to profile MSM and HIV/AIDS in China mainland based on our current information.

\section{DEMOGRAPHIC AND SEXUAL PROFILE OF MSM}

First set of data regarding demographic information of MSM of China mainland was introduced in 1992. Some sociologists found that $7.0 \%$ male college students had homosexual inclination (scholars in China often put bisexuals into homosexuals). A survey in Shanghai reported $8.3 \%$ of male college students had experienced same-gender sex [5]. According to some home and abroad surveys issued in 2002, by 2010, China may have as much as 18 million (10.18-25.45 million) gay and male bisexuals, and $10 \%-15 \%$ of entire male population of China mainland may have experienced the same-gender sex [6]. Another report predicted 39-52 million of gay and lesbian in China [7]. A rigidly designed large-sample survey in 2004 found that 2. $0 \%$ of men aged 20-64 in China mainland self-identified as gay [8]. Surveys on male college students conducted in the same period concluded that $19.8 \%$ of respondents 
experienced same-gender sex, with $36.6 \%$ having occurred before 14 and minus, $33.3 \%$ during $15-18,30.1 \%$ after 19 and plus. $4.3 \%$ of male college students had both homosexual orientation and same-gender sex practice [9]. A report published collaboratively by sociologists and psychohealth experts in 2005 predicated at least 30 million of gay and lesbian in China [10]. From 1950s through mid-1970s, MSM in China had no venues for communication. But some young men in some rural areas had relatively active same-sex activities due to some special folk custom [11]. In the late 1997s, some MSM venues emerged in toilets or parks in major cities. By mid1990s, open gay bars appeared in Beijing and then found their way to other cities. Some major cities even have gay bathrooms and gay dancing halls and underground clubs, causing a shrinking of venues as toilets and parks.

By June 2000, there were 300 plus nationwide or local gay websites [12], some were co-sponsored by Chinese both home and abroad. For instance, a website named ICCGL (www.gaychinese.net) covering news release, commentaries and arts was viewed by 50 thousand readers per day. Most local websites offer personal advertisement service. By mid-2005, number of people accessing internet has climbed to 0.103 billion. There is a gigantic MSM community on the internet. A survey to be published found that about $15.7 \%$ of internet-accessing men $(\mathrm{n}=41878)$ self-deemed as gay or bisexual [13].

The above circumstance provides a platform for spread of HIV among MSM in China. In particular, aftermath of spread of HIV in China differs from those in developed nations, because MSM in developed nations scarcely had sex or get married with women and the spread is confined to MSM community [14]. As for China, $70-80 \%$ of welleducated gays or bisexuals in metropolitan areas has or will get married with women [15]. The proportion in rural areas may climb to $90 \%$ and marriage with women usually becomes inevitable because the incoming severe societal pressure if they do not get married [10], resembling situation in India, or other oriental cultures [16]. The above circumstance indicates that spread of HIV among MSM in China may directly trespass to female population (this kind of transmission has been seen in several internally circulated bulletins from early 1990 s to date).

\section{BEHAVIORAL CHARACTERISTICS OF MSM IN CHINA}

Studies on relation between MSM and AIDS in China normally include routine behavioral surveillance and other compliments. A survey conducted in 1993 on gay use park as venues in four major cities including Beijing revealed that MSM $(n=165)$ had a cumulative sex partner number of 86 people, $77.9 \%$ had one more plus sex partners in the previous year, 53.3\% had experienced sex intercourse with women, they usually had affluent understanding about AIDS, but merely $40.6 \%$ used condoms in the previous year [17].

A survey in 1998 found that MSM $(n=426)$ had a cumulative male sex partner number of 31.6 (median=9). $48.4 \%$ had experienced sex intercourse with women, 12. $7 \%$ paid for sex, $4.9 \%$ were paid for sex, $18.1 \%$ participated in group sex, about two thirds never used condoms, only 2 men persisted in using condom during anal and oral intercourse. A gap between understanding and practice of safe sex was tremendous. Reasons for reluctant to using condom are: reducing pleasure, no risk for infection of HIV, my sex partner is healthy $[18,19]$.

A survey in 2001 found that $85.0 \%$ and $81.9 \%$ of MSM $(\mathrm{n}=1109)$ in the previous year had experienced unprotected active oral intercourse and passive oral intercourse, respectively. $66.2 \%$ and $73.3 \%$ had experienced unprotected active anal intercourse and passive anal intercourse, respectively. $17.1 \%$ kept a one-to-one relation. $45.4 \%$ had sex with accidental strangers; $43.6 \%$ had sex in a place other than his residence. In the previous year $8.3 \%$ paid for sex, $3.0 \%$ were paid for sex, $7.1 \%$ had received fist intercourse, $4.0 \%$ had received bleeding masochism/sadomasochism [20].

In the same period a survey performed in a provincial capital in northeast China revealed that $31.9 \%$ of MSM $(\mathrm{n}=215)$ had cumulative male sex number of 1-10 men, $33.4 \%$ of $11-50,22.1 \%$ of more than 100 . In the previous 6 months, average number of sex partner was 10.3 (median=5), 79.8\% had experienced active anal intercourse, with $41.6 \%$ never using condom during inserting. Only $16.2 \%$ persisted in using condom. $58.7 \%$ had experienced passive anal intercourse with $45.0 \%$ never using condoms, only $13.0 \%$ persisted in using condom. $84.5 \%$ had experienced unprotected anal intercourse, $67.1 \%$ had experienced sexual intercourse with women, only $10.5 \%$ persisted in using condom during sex with women. $19.7 \%$ had paid to men for sex, 3.3\% had paid to women for sex, $21.1 \%$ were paid by men for sex, $2.8 \%$ were paid by women for sex. Only $14.0 \%$ of those who were paid for sex persisted in using condom. $86.9 \%$ believed they were free from infection of HIV or had little chance to be infected [21]. MSM respondents to above data aged 30 on average, living in major cities; half of them had college education background. Several other episodes of surveys on MSM obtained similar results as the 1998's.

A survey conducted via gay website revealed that $70 \%$ of MSM ( $\mathrm{n}=353)$ had sex with men acquired through internet, two thirds of them had experienced unprotected anal intercourse, very few used condom during oral intercourse [22]. 
MSM in some avant-garde major cities used condoms more frequently and had more chances of being tested with HIV [23]. A survey conducted in 2004 in five major cities with similar population told effects of geographic and cultural background onto activities of MSM. In a hip major city located in a plain surrounded by seven middlesized cities, about 5000-7000 men of MSM attended gay venues in weekends of summer, while in another city in a peninsula with conservatives predominant, only 1000 men of MSM do so [24]. Even those never haunted gay venues and those who had one-to-one partner universally had highrisk behaviors [25, 26]. MSM of ethnic minorities were more prone to have sex with women compared to those of Han nationality [27]. MSM who self-identified as bisexual had female sex partner number more than absolute gays and experienced less unprotected passive anal intercourse than absolute gays. Bisexuals less frequently used condoms when had sex with women than with men [28].

It was sociologists, physicians and writers that first turned their eyes to male sex workers (MSW) serving MSM, asserting that number of MSW was beyond estimate of the public and police [29-31]. A survey on MSW $(n=57)$ found that younger, low income or no-income, poor education background and unmarried MSM were more prone to engage in paid sex and MSW had more high-risk behaviors [32]. A to-be-published survey on MSW ( $\mathrm{n}=95$ ) who seek customers in bars found that $74.7 \%$ of them had experienced sex with women, $21.1 \%$ had single woman sex partner, $43.2 \%$ had experienced sex with men, 37 . $9 \%$ had orally taken exhilarants [33].

Researches from international peers suggested that psychological health of MSM relates to social discrimination and social discrimination relates to occurrence of highrisk behaviors [34-38]. A survey found that $62.8 \%$ of MSM $(\mathrm{n}=950)$ in China mainland experienced agony for social discrimination, $57.5 \%$ had been severely reduced life quality, $63.3 \%$ were depressed, $36.3 \%$ had been reprimanded in the wake of disclosure of sexual orientation or same-gender sex, 20.6\% had experienced reprimand from non-MSM, the counterpart number in the previous year was $5.9 \% ; 31.0 \%$ had experienced reprimand from MSM, the counterpart number in the previous year was $14.3 \%$ [39].

The psychiatric circle's survey on MSM $(n=34)$ who self-identified as gay found that $50 \%$ experienced committing suicide [40]. While scholars on AIDS found 9\%$13 \%$ experienced committing suicide, $30 \%-35 \%$ experienced violent suicide attempt [39]. A newly published survey reported that in a sample comprised of self-identified gays and lesbians $(\mathrm{n}=1000), 40.5 \%$ experienced suicide attempt [10]. Another survey found that anxiety and depression rates in gay bar attendants was $45.5 \%$ and 57 .
$5 \%$, respectively, highly associated with high-risk behaviors [41].

A survey on MSM who were absolutely sexually attracted by men and self-identified as gay $(n=240)$ found that a predictor for passive anal intercourse was that "believing a girl identity is better" and "loath to play weaponlike toys during early childhood". Those having sex before 16 years old had more sex partners and more episodes of reprimand in their adulthood. Those did not favor male identity and acted as female role in sex were more prone to passive anal intercourse, strongly associated with cross-gender psycho-behavior situation in early childhood. Those experienced forced intercourse and drug abuse were the most dangerous two subgroups in sexual behavior. Those experienced sex with women had more cumulative sex partners and more chances for group sex. MSM with pedophilia and gerontophilia inner being had more chances having sex with casual sex partners. Discrimination to MSM was associated with suicide attempt and practice [42].

\section{CURRENT STATUS OF HIV/STI AMONG MSM IN CHINA}

Infection cases of HIV among MSM in China initially were only seen in official documents and hospital reports sporadically and accidentally. A document filed in 1990 by the Chinese Ministry of Health accounted an aborigine gay infecting of HIV. Wang and Zhang (1996) reported that 6 in 28 cases of HIV/AIDS confirmed by a major hospital in Beijing during 1985-1996 were MSM [42]. A serial questionnaire surveys on MSM conducted in 1998, 2000 and 2001 revealed that although the respondents were receivers of health-intervention, only $10 \%$ of them received HIV test voluntarily, the infection rate was $2.5 \%, 4.2 \%$, and 5 . $4 \%$, respectively. As end of 2001, MSM in every provinces and major cities of China mainland heard of MSM infection of HIV or already AIDS onset in their locations of residence [6].

A subtype and sequence analysis of the $\mathrm{C} 2-\mathrm{V} 3$ region of env gene of gleaned blood samples during 1998-2001 among HIV-1 infected gay in Beijing found that it was B subtype of HIV-1 that dominated infected MSM in China, whose origin was from Europe or America, having lasted for about 10 years [44]. A special HIV test targeting at MSM of China was introduced in 2001. The test survey in Beijing reported a positive rate of MSM $(n=481) 3.1 \%, 2$. $5 \%$ of the tested were younger than $40,12.1 \%$ were or older than $40.64 \%$ of the testers experienced sex with women. Positive rate of HIV was $1.8 \%$ for those having experienced sex with women and 3.9\% for those not having experienced sex with women. The positive rate for the married was $2.4 \%$, for the unmarried was $6.9 \%$, for those 
having sex partner number less than 20 was $2.0 \%$, and for those having sex partner number 20 or plus was $6.5 \%$ [45].

A survey in 2002 on non-MSW MSM ( $\mathrm{n}=88$ ) living in a major city of south China recruited via internet found HIV infection rate was 3.4\% [46] in contrast to $0.7 \%$ in 2002 and $1.6 \%$ in 2004. Three episodes of HIV test on MSM living in a provincial capital of northeast China in 2001, 2002 and $2004(n=215,140,148)$ found an HIV positive rate $1.32 \%, 1.40 \%$, and $1.35 \%$ respectively, and in MSW in 2004 was $4.76 \%$ [47]. Similar HIV positive rates beyond 1\% were found in Guangzhou and Shenyang [48]. In the second half of 2004, several HIV test surveys conducted in 6 provinces and cities in northeast, east, northwest and southwest China ( $\mathrm{n}>200$ for all samples) reported that infection rates in three cities ranged $1.35 \%-2$. $27 \%$. In another three cities (in peninsula or less avantgarde areas ), no HIV infection was found, however, some cases of HIV infection or onset of AIDS emerged around the surveys, let alone some results closed in closet. The above data indicate that in China mainland that has vast area and population, HIV spread situation among MSM varies with geographic and social elements. For instance, a survey on attendants to gay bar in a provincial capital neighboring Henan province, which is well-known for its AIDS-epidemic due to paid blood donation, the infection rate of the attendants was $4.08 \%(\mathrm{n}=98)$.

Since the end of 2004, CDC of China reiterated via news media that HIV infection rate among MSM was beyond $1 \%$, and MSM has become the second most dangerous group for HIV following injection drug users (IDUs) in China. What comes to attention is that despite HIV infection situation, only $10 \%$ MSM had undergone organized HIV and STI test and questionnaire survey and MSM burdened higher infection rate of syphilis and urethritislike STI.

A survey conducted in Beijing in 2000 found that 23. $8 \%$ of MSM $(n=84)$ had experienced STI, among them one was infected with HIV [49]. Another survey reported a STI rate of $25.8 \%(n=337)$, the incidence in the previous year was $7.7 \%$. The constituent ratio of STI was gonorrhea $21.7 \%$, condyloma acuminata $15.1 \%$, nongonococcal urethritis $14.2 \%$, syphilis $8.5 \%$, genital herpes $4.7 \%$, phthirus pubis $4.7 \%$, HIV $0.9 \%$, blurred diseases $30.2 \%$ [50]. Another survey found that $22.60 \%$ of MSM had been diagnosed as STI, $31.40 \%$ of them experienced gonococcal urethritis, $1.55 \%$ experienced gonococcal ano-rectitis, $1.55 \%$ experienced gonococcal pharyngitis, $25.58 \%$ experienced condyloma acuminata, $24.42 \%$ experienced nongonococcal urethritis, $10.85 \%$ experienced syphilis, $2.71 \%$ experienced genital herpes, $1.93 \%$ experienced chancroid. The constituent ratio was similar to that of the general public [20]. Another test on MSW found that although none of the tested was positive for HIV, the positive rate for genital tract chlamydia trachomatis was $12.6 \%$, for Neisseria gonorrhoeae was $8.4 \%$, for syphilis was $19.5 \%$, and for HSV-2-IgG was 6 . $1 \%[33,51]$.

\section{HEALTH INTERVENTION TO MSM IN CHINA}

In 1992, some of the Chinese health educators called for actions in control of AIDS for MSM living in China. They orchestrated health education activities and offered the first hotline for AIDS help [52, 53]. They emphasized on AIDS intervention to MSM and the indispensable role of NGO made up by MSM $[30,54]$. Unfortunately, their activities were suspended in 1993 and related books and articles were banned. Nevertheless, during this period, a book named Their World came out in 1992, which was written by scholars on sociology described lives of 49 gays living in Beijing; and an academic work named Homosexuality came out whose author was a dermatologist Beichuan ZHANG. In 1994, a mini-seminar on homosexuality and AIDS, organized by scholars on life ethics, was attended by professionals, MSM and governmental officers. In 1997, an intervention program Friend appeared in Qingdao, which was co-sponsored by scholars specializing in AIDS/STI, sociology, psychiatry, life ethics, law and feminism, as well as MSM. The program offers a bimonthly internal pamphlet named Friend Exchange, serving MSM, scholars and the authorities [56], providing information on news, AIDS control and prevention, academic articles, and essays written by gays and lesbians. Publication of articles with topics on MSM was prohibited from 1994-1999 in the Chinese academic journals until 2000. They only can be seen in internal official or non-official materials. By 2000, the issue of respecting the right of MSM was once again suggested by scholars on AIDS/STI [15]. Its potential significance in the prevention and control of AIDS was further elaborated [56]. In early and mid 1990s, several men of MSM in Beijing began to disseminate knowledge of AIDS among MSM in cooperation with some foreigner MSM and lesbians. They opened up the first health promotion hotline in 1997 serving MSM named Beijing Gay/Lesbian Hotline. In the same time, some MSM introduced knowledge about sexual orientation and AIDS to the general public through news media [57]. In 2002, the first licensed Beijing Gender Consultation Center was established, listing AIDSrelated intervention work in the MSM community as one of its top priorities. The center sponsored several workshops training MSM volunteers and non-MSM professionals in many cities as well as handed out some health intervention materials independently or collectively with Chinese Association of STD\&AIDS Prevention and Control. In 2004 
the center held a research study on Methodology for Research on AIDS Intervention in MSM Community, which was endorsed by the MSM community, academic circle and the authorities. It was regarded as a milestone indicating a transfer of backbone undertaker of intervention work from academic circle to MSM community [58].

In the same period, the program Friend, Chinese Association of STD\&AIDS Prevention and Control, Beijing Gay/ Lesbian Hotline co-sponsored two sessions of seminars on MSM/AIDS in 2000 and 2003. The pamphlet Friend Exchange (each print run produced 10 thousand copies in 2001) two times staged Consensus \& Proposal vowing for a concern on AIDS among MSM, help and support to fight against the disease, and a sensible attitude toward intervention works. In 2001, some MSM formally attended first session of China Conference for Control and Prevention of AIDS/STD, and their articles were included into the selected articles of the conference. In 2003, Chinese Association of STD\&AIDS Prevention and Control established a Committee of Volunteers and some of the MSM were main participants of this committee.

From 2002 to date, about 20 major cities have established workshops principally comprised of MSM and technically assisted by some professionals. The workshops have their own offices and relatively full-time personnel serving outdoors service at gay venues, hotline help, and fellowship activities aimed at raising awareness of AIDS. The workshops fall apart into several types: (1) teams in the charge of MSM: Chengdu and Shenyang; (2) teams in the charge of health service professionals: Chongqing and Shanghai; (3) teams in the charge of local authorities: Zhejiang and Heilongjiang. In 2002, some grassroots AIDS professionals established the Aizhixing Health Education Institute with emphasis on AIDS intervention. The teams are predominantly funded by some oversea foundations. Some NGOs comprised of oversea Chinese also carried out related work in some cities. However, some of those activities were declined in the MSM communities partially due to the lack of focus on MSM. It proves that health intervention to MSM plays a positive role in changing highrisk behavior and improving psychological health $[39,59]$.

Realizing China is on a critical turning point, scholars appealed to the authorities to give political, financial and networked support to health education works for MSM [60]. The Chinese Ministry of Health in its 2005' document demanded its CDC institutions to carry out health intervention and to help MSM, hoping HIV rampancy among MSM could be reduced within the upcoming several years.

\section{ELEMENTS AFFECTING SPREAD AND CON- TROL OF HIV AMONG MSM}

In view of tradition and current status, at least four factors play roles in spread and control of HIV among MSM in China. (1) a mainstream belief on relation between fertility and sex that is inherited from belief as early as the twentieth century; (2) Ideologized and stereotyped same-gender sex and its residual effects, beginning politically and culturally from 1900-1970; (3) Effects on understanding of same-gender sex of China's Opening and Reform Policies beginning from 1980 and the globalization trend in the world; (4) Development of China's society and their response to AIDS.

Strikingly different from those nations that are under the umbrella of Christian or Islam religions that still punish MSM [61], never has China a repulsive tradition against MSM until the nineteenth century. However, the custom demanded that sexual relation between men not interfere marriage and fertility with women. It was from early twentieth century, which was during reign of Kuomintang, that man-man sex was labeled unethical and punished by law [62]. As early as 1957, the supreme court of China in its document stated that consented same-gender sex between adult men was not criminal. In 1993, the Ministry of Public Security restated this opinion. However, man-man sex was ideologized and stereotyped during 1950-1970s, regarded as a cultural threat from western nations. While during 1950-1990s, viewpoints of early western psychiatry circle on homosexuality entered China, listing it as a psychological disorder. The 1980's Opening and Reform Policies and 1990's globalization trend helped DSM-II, DSM-III and ICD-10 enter into China and exert influence. Meanwhile, news about epidemic among MSM in western nations was hyped.

In 1987, the authorities stated that man-man sex was scarce in China, it violated mores and laws, and it was unlikely that AIDS would spread in China [63]. And documents in the same period ordered a very strict ban on homosexuality. This conservative attitude fundamentally changed at the end of 1990s. In 2001, CCDM-3 struck self-agreeable homosexuality from a list of psychiatric disorders [64]. However, these changes took little effects on the public. The principal pressure that the MSM endure is from non-official elements, that is to say, parents and relatives nagging them to get married. It is believed that a diversified sexual value will emerge, with decaying of traditional forces that control sexual activities, and influence of China's family planning policy, boom of market economy and urbanization of China. The migrations and impact of sexual revolution help MSM improve their life quality, but as a double blade sword, they will provide greenhouse for the spread of HIV. The factors baffling halting spread of HIV among MSM are as followings: political omission, backward human rights status regarding 
sexual orientation, weak power of the academic circle on policy making, and unfledged subculture of MSM [65]. Due to the negligence to bitter flaws that the peer nations had suffered, lacking knowledge about national situation and inefficient reaction to AIDS, and a severe epidemic of AIDS occurred among IDUs and paid blood donors in China mainland. Although China still enjoys a less severe HIV/AIDS prevalence than Thailand around 1990 and India today. Nevertheless, China authorities are already getting vigilant toward spread of HIV by female sex workers and MSM, by introducing new changes of policy, which are propelling intervention activities targeting at MSM. Thankful to China's new development in culture, politics and economy, China is on a right course in fighting against HIV/AIDS in MSM.

\section{SUMMARY}

MSM in China have been becoming active since 1980s, breaking silence and isolation. Some open or semi-open MSM groups turned up. Activities regarding MSM were more and more acceptable to the general public in real life and on internet. However, universal presence of high-risk behaviors and HIV spread trend do not allow optimism. Although current HIV seroprevalence rate in China is far lower than that in the developed nations as in the 1980s, a particular situation for China is that MSM in China are more prone to spread HIV to women. Fertility-emphasized custom and unique complicacy of politics, economy and culture play a modulating role in spread and control of HIV among MSM in China mainland. Fortunately, China's academic circles, MSM community and the authorities begin to make active responses. What is more important is that MSM are changing their roles from being subordinate and passive receivers of health education and intervention to playing active and positive roles in these processes. Facing many obstacles on its way to fight against AIDS among MSM, China is at a critical turning point. Proper and positive actions could possibly halt HIV transmission among MSM from its current rampancy.

\section{REFERENCES}

1 China Ministry of Health and UN Theme Group on HIV/AIDS in China. A joint assessment of HIV/AIDS prevention, treatment and care in China. 2003:12.

2 China Ministry of Health and UN Theme Group on HIV/AIDS in China. A joint assessment of HIV/AIDS prevention, treatment and care in China. Beijing 2004: 7.

3 Chen Minzhang. Probe into the effective intervening measure, controlling AIDS prevailing in China. Collection thesis of "China's AIDS intervening measure seminar" (China Preventive Medical Science Institute). Beijing 1997:3-4.

4 Kaufman, Jing J. China and AIDS - the time to act is now. Science 2002; 296:2320-4.
5 Liu DL, Qiu LP. Sexual behavior in modern China - a report of the nation-wide "sex civilization" survey on 20,000 subjects in China. Shanghai: Sanlian Bookstore 1992:201-7.

6 Zhang BC, Li XF, Shi TX, et al. A preliminary estimate to population size and HIV infection rate among male homosexuals/bisexuals in China. Chin J STD/AIDS Prev Cont 2002, 8:197-9.

7 Li YH.The reaserch paper of sexual culture.Nanjing: Jiangsu People's Press 2003:117.

8 Pan SM, Parish W, Wang AL, Edward OL. Sexual behavior and relation in contemporary China. Beijing: Publishing House of Social Scientific Literature 2004:331-2.

9 Pan SM, Yang R.Sexuality of Chinese college students:A tenyear longitude nationwide random study. Beijing: Publishing house of social scientific literature 2004:160-72.

10 Liu DL, Lu LG. Homosexuality reaserch in china. Beijing: China Social Press 2005: 47, 73, 274.

11 Wang WG (Tong Ge). Let your children fly away: reveal the secrets of how to educate your children. Shijiazhuang: Science Tech Publishing House of Hebei 2002:288-91.

12 Edward. China homosexual website and AIDS prevention .Friend 2001; 4:15-25.

13 Ma XN, Yang DZ, Lin SQ, Zhu JC. Internet investigation of China's human nature health status in 2004. J Repro Med. in press.

14 Dubois-Arber F, Masur JB, Hausser D, Zimmermann E, Paccaud F. Evaluation of AIDS prevention among homosexual and bisexual men in Switzerland. Soc Sci Med 1993, 37: 1539-44.

15 Zhang BC, Li XF, Hu TZ, Liu DC, Shi TX. HIV/AIDS interventions targeting men who have sex with men (MSM) :theory and practice. Chin J STD/AIDS Prev Cont 2000; 6:155-7.

16 Kumar B, Ross MW. Sexual behavior and HIV infection risks in Indian homosexual men: a cross-cultural comparison. Int J STD AIDS 1991; 2:442-4.

17 Pan SM. Sex Actuality in China. Beijing: Guangming Daily Press 1995; 428-35.

18 Zhang BC, Liu DC, Li XF, Hu TZ. A survey of men who have sex with men: mainland China. J Am Public Health 2000; 90: 1949-50.

19 Zhang BC, Liu DC, Li XF, Hu TZ. AIDS-related high-risk behaviors and affecting factors of men who have sex with men (MSM) in Mainland China. Chin J Sex Transm Inf 2001; 1:7-16.

20 Zhang BC, Li XF, Shi TX, Cao NG, Hu Tiezhong.Survey on the high risk behaviors and other AIDS/STI related factors among men who have sex with men (MSM) in mainland China (2001). Chin J Dermatol 2002; 35:214-6.

21 Qu SQ, Zhang DP, Wu YH, Zhu H, Zheng XW. Seroprevalence of HIV and risk behavior among men who have sex with men in a northeast city of China. Chin J STD/AIDS Prev Cont 2002; 8: 145-7.

22 Wang QY, Ge L, Michael WR. Sexual behaviors among men who have sex with men:an internal outreach sample. Chin J STD/ AIDS 2004; 10:335-7.

23 Shi TX, Zhang BC, Li XF, Cao NX. Research on the High risk behaviors and other AIDS/STI related factors among men who have sex with men (MSM) in Mainland China. Proceedings of the First National STD and Skin Disease Congress of the 21st Century. The Supplement of Chin J STD/AIDS Prev Cont 2001; $130-4$.

24 Zhang BC. Survey of AIDS prevention on homosexual men. Working communication of AIDS expert consultative committee of 
Public Health (internal communication), NO.3, 2004:130-4.

25 Shi TX, Zhang BC, Li XF, Hu TZ, Cao NX. A study on the relationship between the way of sex touch and AIDS high risk behaviors in MSM.U.S-Chin J Dermatol 2003; 1:49-53.

26 Zhang JD, Yan HH, LI XF, Zhang BC. Survey of high risk behaviors related to AIDS among men who have sex with their regular male sex partners. Chin J STD/AIDS 2003; 9:84-6.

27 Zhu MQ, Zhang BC, Li XF, Shi TX, Wu SW. High risk behaviors related HIV/AIDS and Nationality Variables of men who have sex with men in china .Chinese journal of the practical Chinese with Modern Medicine 2004; 4:2334-6.

$28 \mathrm{Wu}$ SW, Zhang BC, Li XF. AIDS high risk behavior surveillance and comparison of homosexual/bisexual men in china. Chin $\mathrm{J}$ STD/AIDS 2004; 10:332-4.

29 Li YH, Wang XB. Their World-Perspecting on Chinese homosexual men. Taiyuan: Shanxi People's Press 1992:226-227.

30 Wan YH. Several viewpoints of AIDS education to the homosexual men. Chin J Health Educ 1992; 8:35-7.

31 Fang G.The Menace of AIDS approaching Mainland China. Changchun:Jilin People's Publishing House 1995: 199-209.

32 Zhang BC, Wu SW, Li XF, Zhu MQ, Yang LG. Study on high risk behaviors among male sex workers related to STI/HIV. Chin J STD/AIDS 2004; 10:329-31.

33 QI SZ, Zhang GC, Cao NX, et al. Urine-checking Chlamydia trachomatis, Neisseria gonorrheae and the analysis of the risk factors. Chin J Dermatol, in press.

34 Warner J, McKeown E, Griffin M, et al. Rates and predictors of mental illness in gay men, lesbians and bisexual men and women: Results from a survey based in England and Wales. Br J Psychiatry 2004; 185:479-85.

35 Huebner DM, Rebchook GM, Kegeles SM. Experiences of harassment, discrimination, and physical violence among young gay and bisexual men. Am J Public Health 2004; 94:1200-3.

36 Diaz RM, Ayala G, Bein E, Henne J, Marin BV. Sexual risk as an outcome of social oppression: data from a probability sample of Latino gay men in three U.S. cities. Cultur Divers Ethnic Minor Psychol 2004; 10:255-67.

37 Yoshikawa H, Wilson PA, Chae DH, Cheng JF. Do family and friendship networks protect against the influence of discrimination on mental health and HIV risk among Asian and Pacific Islander gay men? AIDS Educ Prev 2004; 16:84-100.

38 Wilson PA, Yoshikawa H. Experiences of and responses to social discrimination among Asian and Pacific Islander gay men: their relationship to HIV risk. AIDS Educ Prev 2004; 16:68-83.

39 Zhang BC, Li XF, Wu SW, et al. Survey of homosexual and bisexual male's psychology and related condition in China today. The Chin J Hum Sex 2003; 12:16-8.

40 Liu HQ, Zhang PY, Zhou YZ, et al. Psychological analysis of homosexuality and other effecting factors.Chin J Psychiatry 1999; 4:242-4.

41 Zheng YJ, Xu J, Zhang HB. The relationship between anxiety, depression and high-risk behaviors among MSM.Chin J Mental Health, in press.

42 Zhang BC, Hu TZ, Li XF, Shi TX, Liu DC. The relationship between AIDS high risk behaviors and childhood status, perception of gender orientation and rare experiences/psychology among Chinese gays. Chin J Sex Transm Inf 2002; 2:1-10.

43 Wang AX, Zhang WH. The clinical diagnosis of 28 people with HIV/AIDS. Chin J STD/AIDS Prev Cont 1996; 2:276-7.
44 Yao J, Zhang FJ, He ZP, et al. Subtype and sequence analysis of the C2-V3region of env gene among HIV-1 infected homosexual men in Beijing. Chin J STD/AIDS Prev Cont 2002; 8:131-3.

45 Kyung-Hee C, Liu H, Guo YQ, et al. Emerging HIV-1 epidemic in China in men who have sex with men. Lancet 2003; 361:2125-6.

46 Yang ZF, Fang SN, Cai WD, Duan LH. Survey on syphilis and HIV infection and sexual behavior among men having sex with men. Chin J Public Health 2003; 19:1292-3.

$47 \mathrm{Wu}$ YH, Liu YC, Zhao ZH, et al. The estimate of gay population and the analysis of HIV prevalence in a city of Heilongjiang. Chin J Public Health and management, in press.

48 China Ministry of Health and UN Theme Group on HIV/AIDS in China. A joint assessment of HIV/AIDS prevention, treatment and care in China (2004). Beijing 2004; 10.

49 Liu H, Liu Y, Xiao Y. Survey on knowledge, attitude, belief and practice related to HIV/AIDS among MSM. China Ministry of Health and UN Theme Group on HIV/AIDS in China. A joint assessment of HIV/AIDS prevention, treatment and care in China 2001; 7:289-91.

50 Li XF, Zhang BC, Liu DC, Zhou XB, Hu TZ. Survey of STD prevalence and related high risk behaviors in china MSM.Chin J dermatol 2001; 34:189-91.

51 Qi SZ, Zhang GC, Cao NX, et al. Serological investigation of HIV/AIDS and related risk factors associated in male sex workers. China J Lepr Skin Dis, in press.

52 Chen BZ, Wan YH, Zheng BC, Wang Q. The AIDS hot line for help on developing. 1993, 9:34-7.

53 Chen B. AIDS, homosexuality, health education. Chin J Health Educat 1993; 9:9-16.

54 Wan YH. Develop the role of non-government organization on AIDS control. Chin J Health Educat 1992; 8:9-11.

55 The UN Theme Group on HIV/AIDS in China. HIV/AIDS: China's Titanic Peril-2001 Update of the AIDS Situation and Needs Assessment Report. UNAIDS China Office 2002; 39.

56 Zhang BC. Homosexuality, the policy of AIDS and human rights construction. Chin J Hum Sex 2004; 13:35-7.

57 Wang Weigang (Tong Ge). To a reader who suspect himself have AIDS. Beyond Eight Hours 1995:51-2.

58 Zheng LQ. The report come from homosexuals. Health Newspaper, November 29, 2004.

59 Zhang BC, Li XF, Hu TZ, Liu DC, Cao NX. "Friend Communication" program-an Effective AIDS Intervention Program for MSM. Chin J Health Educat 2001; 17:206-10.

60 Zhang BC. HIV/AIDS interventions targeting men who have sex with men (MSM) : background, practice and support Proceedings of the First National STD and Skin Disease Congress of the 21 st Century (The Supplement of Chin J STD/AIDS Prev Cont) 2001:413-5.

61 Helie A. Holy hatred. Reprod Health Matters 2004; 12:120-4.

62 An KQ. Dirty soul under the red sun: Gay's live report in China's Mainland. Taibei: Reai Limited Company for Publish, 1997:85.

63 Pan SM. The sexual life during AIDS era. Guangzhou: Publishing house of South Daily 2004: 250-1.

64 Psychiatric department of Chinese Medical Association. Diagnostic criteria of mental disorders (CCMD-3). Jinan: Scientific and Technological Publishing House of Shandong, 2001:1.

65 Zhang Beichuan. The disadvantages for the AIDS prevention and control among MSM. Chin J STD/AIDS Prev Cont 2003; 9: 379-81. 